6. Fortin M, Bravo G, Hudon C, Vanasse A, Lapointe L. Prevalence of multimorbidity among adults seen in family practice. Ann Fam Med. 2005;3(3):223-228.

7. Stange KC. The paradox of the parts and the whole in understanding and improving general practice. Int J Qual Health Care. 2002;14(4):267-268

8. Stange KC. The problem of fragmentation and the need for integrative solutions. Ann Fam Med. 2009;7(2):100-103.

9. Fortin M, Lapointe L, Hudon C, Vanasse A. Multimorbidity is common to family practice: is it commonly researched? Can Fam Physician. 2005;51:244-245.

10. Mercer SW, Smith SM, Wyke S, O'Dowd T, Watt GC. Multimorbidity in primary care: developing the research agenda. Fam Pract. 2009;26(2):79-80.

11. Fortin M, Soubhi $H$, Hudon C, Bayliss EA, van den Akker M. Multimorbidity's many challenges. BMJ. 2007;334(7602):1016-1017.

12. Valderas JM, Starfield B, Sibbald B, Salisbury C, Roland M. Defining comorbidity: implications for understanding health and health services. Ann Fam Med. 2009;7(4):357-363.

13. Rich EC, Lipson D, Libersky J, Peikes DN, Parchman ML. Organizing care for complex patients in the patient-centered medical home. Ann Fam Med. 2012;10(1):60-62.

14. Agency for Healthcare Research and Quality (AHRQ). Coordinating care for adults with complex care needs in the patientcentered medical home: challenges and solutions. 2011. http:// pcmh.ahrq.gov/portal/server.pt/community/pcmh__home/1483/ PCMH_Home_Papers\%20Briefs\%20and\%200the\%20Resources_v2.
15. Stange KC. A science of connectedness. Ann Fam Med. 2009;7(5): 387-395.

16. Stange KC. The generalist approach. Ann Fam Med. 2009;7(3): 198-203.

17. Jerant A, Fenton JJ, Franks P. Primary care attributes and mortality: a national person-level study. Ann Fam Med. 2012;10(1):34-41.

18. Hoebert JM, Souverein PC, Mantel-Teeuwisse AK, Leufkens HGM, van Dijk L. Reimbursement restriction and moderate decrease in benzodiazepine use in general practice. Ann Fam Med. 2012;10(1):42-49.

19. Mangin D, Murdoch D, Wells JE, et al. Chlamydia trachomatis testing sensitivity in midstream compared with first-void urine specimens. Ann Fam Med. 2012;10(1):50-53.

20. Delaney BC, Peterson KA, Speedie S, Taweel A, Arvanitis TN, Hobbs FDR. Envisioning a learning health care system: the electronic Primary Care Research Network, a case study. Ann Fam Med. 2012;10(1):54-59.

21. Baskerville NB, Liddy C, Hogg W. Systematic review and metaanalysis of practice facilitation within primary care settings. Ann Fam Med. 2012;10(1):63-74.

22. Pust RE. Indication. Ann Fam Med. 2012;10(1):75-78.

\title{
EDITORIAL
}

\section{Simplifying Care for Complex Patients}

\author{
Elizabeth A. Bayliss, MD, MSPH, Associate Editor \\ Institute for Health Research, Kaiser Permanente, Denver, Colorado
}

Ann Fam Med 2012;10:3-5. doi:10.1370/afm.1352.

$\mathrm{T}$ The challenge of delivering patient-centered care to complex patient populations is to provide the right care for the right person at the right time. Our ability to do so is contingent upon accurately identifying specific populations, assessing their care needs, and developing models to meet those needs.

In this issue of the Annals, 3 investigations illustrate

Conflicts of interest: author reports none.

\section{CORRESPONDING ADDRESS}

Elizabeth A. Bayliss, MD, MSPH

Institute for Health Research

Kaiser Permanente

10065 E Harvard Ave, Ste 300

Denver, CO 80231-5968

Elizabeth.Bayliss@KP.org the value of targeting clinician, patient, and system behavior as interrelated paths to improvement in health outcomes in complex patient populationsspecifically populations with depression plus other chronic conditions.

These articles present evidence from randomized controlled trials to inform different aspects of caring for patients with depression plus other comorbid conditions: Lin et al describe the positive effect of a team-based care intervention on initiation and adjustment of pharmacotherapy for persons with depression plus diabetes and/or coronary heart disease, ${ }_{1}^{1}$ Bogner et al use integration care managers to improve medication adherence and subsequent disease outcomes for persons with depression and diabetes, ${ }^{2}$ and Morris et al show that the effectiveness and side-effect profiles of different antidepressant medication regimens are 
unaffected by the number of conditions comorbid with major depressive disorder. ${ }^{3}$

Previous interventions to reduce depression symptoms in primary care found that the most effective interventions incorporated clinician education, nurse care management, and integration between primary and specialty care. ${ }^{4}$ Care managers served multiple roles, which included patient educators (on a range of topics from medication adherence to treatment duration), interpreters of care plans to patients, monitors of therapy, and conduits for patient concerns to both primary clinicians and mental health consultants. ${ }^{4 \cdot 7}$

The interventions described in the articles by Lin et al and Bogner et al expand on these models and have care managers (I use the term loosely to include core members of care teams and integration managers, as in the Lin et al and Bogner et al trials) provide education and expertise on depression, as well as specific additional comorbidities. The effectiveness of these care models in these settings raises 2 additional questions: Can these models of care be extended to other populations of persons with multiple chronic medical conditions (with and without depression), and which health outcomes would illustrate the success of such care models?

For the substantial population of persons with depression plus a range of chronic conditions, care models directed at treating depression alone may benefit other conditions as well. For example, Lin et al and others have previously shown that depression care management has the potential to improve multiple symptom domains. ${ }^{8-10}$ Further, patient populations with multiple morbidities and depression may be more responsive to general self-management interventions than are populations with no depression and fewer medical conditions. ${ }^{11,12}$ Thus, there seems to be little doubt that care management attending to depression and other conditions has the potential to improve several health outcomes for both conditions.

Generalizing such care models to more heterogeneous populations of complex patients, however, will require identifying components of interventions that may be effective regardless of patients' medical conditions. In the interventions described in this issue, care managers enhance 2 elements of care infrastructure that may be foundational for complex patient care: communication and continuity between patients and clinicians. Included are additional patient assessment time, individualized patient coaching about self-care and goal attainment, and facilitating conversations about decision making between primary care and specialty clinicians and between clinicians and patients.

Although such enhanced communication may or may not improve disease-specific self-care and outcomes, it may still promote patient-centered care for complex patients. Conversations with seniors with a range of multimorbidities have revealed that, for them, ideal care would include convenient access to clinicians (including by telephone or Internet), communication of individualized care plans, and support from a single coordinator of care who could help patients prioritize the competing demands from their multiple conditions. ${ }^{13}$ Other concerns of complex patients that may be addressed through general care management include making sense of information from multiple sources, prioritizing self-management strategies, navigating interactions with clinicians and systems, improving understanding of medications, and helping patients establish connections between different care recommendations. ${ }^{14-16}$

The effectiveness of generalizing disease-specific interventions for patients with comorbidities to the broader population of patients with a range of multiple morbidities will depend on the outcomes assessed. For complex patients with symptomatic depression, it is unlikely that any health outcomes will improve without active management of the depression. Based on the Lin et al, Bogner et al, and Morris et al articles, depression management should include active care management, incorporating medication adherence and treatment intensification strategies, broad self-management support, and enhanced communication with patients and between patients and the other members of the care team.

Beyond successful treatment of depression, evaluating successful care depends on our ability to identify and assess outcomes that matter to patients as much as outcomes that matter to their clinicians. Medication adherence, treatment intensification, treatment adjustment, and self-monitoring behaviors (outcomes in all 3 articles in this issue) matter (on different levels) to both clinicians and patients-assuming that, to the patient, the benefits (such as symptom improvement and self-efficacy with condition management) outweigh any perceived adverse effects of treatment. Other outcomes that are likely meaningful to both patients and clinicians include decreases in symptom burden, improvements in functioning, and individual goal attainment. Such outcomes should also be evaluated as evidence of effective patient-centered care delivery. It is likely that providing continuous, cohesive care management would facilitate the identification of such outcomes that are particularly meaningful to complex patients, as well as the shared decision making with clinicians required to attain them.

Current reimbursement structures do not encourage multidimensional care management and encourage measuring only disease-specific outcomes. This disease-specific perspective for reimbursement may 
change with increased attention to a more comprehensive assessment of the process and outcomes of patientcentered care. ${ }^{7,17,18} \mathrm{~W}$ ith this shift, it may become not only medically correct but also financially feasible to implement effective integrated and multidimensional care management for persons with depression and other chronic medical conditions.

To read or post commentaries in response to this article, see it online at http://www.annfammed.org/content/10/1/3.

Key words: Depression, comorbidity, medication adherence; chronic disease; primary health care; care management

Submitted November 10, 2011; submitted, revised, November 11, 2011; accepted November 11, 2011.

\section{References}

1. Lin EHB, Von Korff M, Ciechanowski P, et al. Treatment adjustment and medication adherence for complex patients with diabetes, heart disease, and depression a randomized controlled trial. Ann Fam Med. 2012;10(1):6-14.

2. Bogner HR, Morales KH, de Vries HF, Cappola AR. Integrated management of type 2 diabetes mellitus and depression treatment to improve medication adherence: a randomized controlled trial. Ann Fam Med. 2012;10(1):15-22.

3. Morris DW, Budhwar N, Husain M, et al. Depression treatment in patients with general medical conditions: results from the CO-MED trial. Ann Fam Med. 2012;10(1):23-33.

4. Gilbody S, Whitty P, Grimshaw J, Thomas R. Educational and organizational interventions to improve the management of depression in primary care: a systematic review. JAMA. 2003;289(23):3145-3151.

5. Hunkeler EM, Katon W, Tang L, et al. Long term outcomes from the IMPACT randomised trial for depressed elderly patients in primary care. BMJ. 2006;332(7536):259-263.

6. Rollman BL, Belnap BH, LeMenager MS, et al. Telephone-delivered collaborative care for treating post-CABG depression: a randomized controlled trial. JAMA. 2009;302(19):2095-2103.
7. Nutting PA, Gallagher K, Riley K, et al. Care management for depression in primary care practice: findings from the RESPECTDepression trial. Ann Fam Med. 2008;6(1):30-37.

8. Lin EH, Katon W, Von Korff M, et al; IMPACT Investigators. Effect of improving depression care on pain and functional outcomes among older adults with arthritis: a randomized controlled trial. JAMA. 2003;290(18):2428-2429.

9. Piette JD, Richardson C, Himle J, et al. A randomized trial of telephonic counseling plus walking for depressed diabetes patients. Med Care. 2011;49(7):641-648.

10. Bogner HR, de Vries HF. Integration of depression and hypertension treatment: a pilot, randomized controlled trial. Ann Fam Med. 2008;6(4):295-301.

11. Harrison M, Reeves D, Harkness E, et al. A secondary analysis of the moderating effects of depression and multimorbidity on the effectiveness of a chronic disease self-management programme. Patient Educ Couns. 2011. Jul 16 [Epub ahead of print].

12. Jerant A, Kravitz R, Moore-Hill M, Franks P. Depressive symptoms moderated the effect of chronic illness self-management training on self-efficacy. Med Care. 2008;46(5):523-531.

13. Bayliss EA, Edwards AE, Steiner JF, Main DS. Processes of care desired by elderly patients with multimorbidities. Fam Pract. 2008; 25(4):287-293.

14. Morris RL, Sanders C, Kennedy AP, Rogers A. Shifting priorities in multimorbidity: a longitudinal qualitative study of patient's prioritization of multiple conditions. Chronic IIIn. 2011;7(2):147-161.

15. Corser W, Dontje K. Self-management perspectives of heavily comorbid primary care adults. Prof Case Manag. 2011;16(1):6-15, quiz 16-17.

16. Jowsey $T$, Jeon YH, Dugdale P, Glasgow NJ, Kljakovic M, Usherwood T. Challenges for co-morbid chronic illness care and policy in Australia: a qualitative study. Aust New Zealand Health Policy. 2009;6:22.

17. National Quality Forum. Preferred Practices and Performance Measures For Measuring and Reporting Care Coordination: A Consensus Report. Washington, DC: National Quality Forum; 2010.

18. Patient-Centered Outcomes Research Institute. http://www.PCORI .org. Accessed Nov 1, 2011. 